\title{
Identification of novel cadherin 23 variants in a Chinese family with hearing loss
}

\author{
TIANNI XU, WEI ZHU, PING WANG, HAONAN LI and SHUYUAN YU \\ Department of Otolaryngology-Head and Neck Surgery, The First Hospital of Jilin University, \\ Changchun, Jilin 130021, P.R. China
}

Received September 28, 2018; Accepted May 9, 2019

DOI: $10.3892 / \mathrm{mmr} .2019 .10503$

\begin{abstract}
The aim of the present study was to elucidate the role of the non-syndromic autosomal recessive deafness 12 allelic variant of cadherin $23(\mathrm{CDH} 23)$ in Chinese patients with non-syndromic hearing loss. The present study focused on a Chinese family with hearing loss in which there were two siblings with autosomal, recessive deafness, ranging from severe to profound hearing loss over all frequencies. DNA sequencing was used to assess the genetic factors in the disease etiology. The data revealed a compound heterozygous mutation of $\mathrm{CDH} 23$ in both patients. Genetic $\mathrm{CDH} 23$ variants are known to be responsible for non-syndromic hearing loss, and $\mathrm{CDH} 23$ variants frequently occur in various populations, including Japanese and Republic of Korean. Results from the present study, indicated a significant contribution of $\mathrm{CDH} 23$ variants to the non-syndromic hearing loss in Chinese patients.
\end{abstract}

\section{Introduction}

Hearing loss or hearing impairment refers to a partial inability to hear sounds in one or both ears, while deafness is defined by full inability to hear (1). The Global Burden of Disease Study has demonstrated that hearing loss is the fourth leading cause of global disability (2). In the United States, the prevalence of hearing loss doubles every 10 years with an increasingly aging population (3). Risk factors for hearing loss include genetic factors, aging, a noisy environment, ear trauma or infection, birth complications, certain medications and toxins (1). Genetic factors may be responsible for $\sim 40 \%$ of childhood hearing loss, especially in children born of consanguineous marriages (4-6). Hundreds of gene mutations have been identified that lead to hearing loss either as an exclusive clinical

Correspondence to: Dr Wei Zhu, Department of OtolaryngologyHead and Neck Surgery, The First Hospital of Jilin University, 3808 Jiefang Road, Changchun, Jilin 130021, P.R. China

E-mail: zhuwei3000@hotmail.com

Key words: cadherin 23, non-syndromic autosomal recessive deafness 12 , non-syndromic hearing loss, genetic variants feature or in combination with extra-auditory symptoms as part of a syndrome (7). Non-syndromic forms of deafness account for $70 \%$ of cases, of which $\sim 85 \%$ are inherited in an autosomal recessive manner $(8,9)$. Owing to recent improvements in research of genetic factors, such as the identification of gene mutations involved in congenital hearing loss, genetic counseling has emerged and increased in availability (1). High-throughput DNA sequencing technologies, known as next-generation DNA sequencing or massively parallel sequencing, are used to detect multiple gene mutations, which results in improved detection and early treatment of childhood hearing loss (10).

Recessive genetic mutations of cadherin $23(\mathrm{CDH} 23)$ have been associated with the allelic variants Usher syndrome type 1D (USH1D) and non-syndromic autosomal recessive deafness 12 (DFNB12) $(11,12)$. CDH23 is on chromosome 10q21-q22 and contains 69 exons that encode the CDH23 protein. $C D H 23$ comprises 3,354 amino acids with 27 cadherin extracellular (EC) repeats, a single transmembrane domain and a short unique cytoplasmic domain (12). Each EC domain of the $\mathrm{CDH} 23$ protein contains several cadherin-specific amino acid motifs, such as LDRE, DXD and DXNDN, and is highly conserved in sequence and spacing, which is required for cadherin dimerization and calcium-binding (13). CDH23 mutations induce disorganization of the stereocilia in the hair cells of the inner ear in the 'waltzer' mouse model of the USH1D (14). Thus, the extracellular domains of CAD23 are crucial for the correct morphogenesis of hair bundles in the inner ear neurosensory cells, whereas the cytoplasmic domain of the CDH23 interacts with other hair bundle proteins, including myosin VIIA and harmonin $(15,16)$. However, an increasing number of genetic variants of different genes have been reported, such as USH1D and DFNB12 (17-20). Certain gene variants occur with a distinct frequency in different populations. For example, two variants were screened in patients with a Swedish background (17), whereas others were present in Japanese or Korean subjects (18-20). The aim of the present study was to elucidate the role of the DFNB12 $\mathrm{CDH} 23$ mutation in Chinese patients with non-syndromic hearing loss. The nature of diverse $C D H 23$ mutations and their resulting phenotypes in hearing loss were studied using a comprehensive strategy that included DNA sequencing and bioinformatics, which provided information regarding hearing loss in Asian populations. 


\section{Materials and methods}

Study subjects. The study was approved by the Ethics Committee of the First Hospital of Jilin University (Changchun, China) and all participants provided written informed consent prior to being enrolled in the study. The study enrolled two patients (II:1 and II:2) with severe sensorineural hearing loss and their parents (I:1 and I:2). Clinical information and peripheral blood samples were acquired for DNA extraction and DNA sequencing. The patients were diagnosed using audiologic tests according to the American College of Medical Genetics and Genomics guidelines (21). Linkage analysis was not carried out owing to the small number of participants.

DNA extraction and DNA sequencing. Genomic DNA was extracted from the blood samples using a TIANamp Blood DNA Kit (TianGen Biotech Co., Ltd.) and quantified using a Nanodrop 2000 spectrophotometer (Thermo Fisher Scientific, Inc.) according to the manufacturer's protocol. Subsequently, the genomic DNA samples were subjected to DNA sequencing focusing on nine gene loci: GJB2:35delG, 176del16, 235delC, 299delAT, GJB3:538C >T, SLC26A4:2168A>G, IVS7-2A>G, mitochondrial 12SrRNA:1494C $>\mathrm{T}$ and $1555 \mathrm{~A}>\mathrm{G}$, using the LuxScan 10K Microarray Scanner (CapitalBio Corporation). A customized exome enrichment kit (MyGenostics, Inc.) was designed to identify genes that induce hearing loss. The prepared samples were sequenced using Illumina NextSeq 500 (Illumina, Inc.).

DNA libraries were constructed using the genomic DNA samples with a Library Preparation kit (MyGenostics, Inc.), according to the Illumina platform requirements. The enzymatic fragmentation of genomic DNA samples was end-repaired, and adapters were added. The length of the prepared libraries was $\sim 350-400 \mathrm{bp}$, and they were amplified by PCR and analyzed using an Agilent 2100 Bioanalyzer (Agilent technologies Inc.) by MyGenostics, Inc. The aligned short reads were compared with the human reference genome (hg19) (http://hgdownload.cse. ucsc.edu) using the Burrows-Wheeler Aligner (version 0.7.15; http://bio-bwa.sourceforge.net/). The quality control assessment and variant calling were processed using the Genome Analysis Toolkit (GATK; version 3.6; https://www.broadinstitute. org/gatk/) following GATK best practices (22) and annotated using ANNOVAR (version 2016-02-01), similarly to a previous study (23). Potential damaging gene variants were screened for quality against the 1000 Genomes public variant databases (ftp://ftp.1000genomes.ebi.ac.uk/vol1/ftp), the Single Nucleotide Polymorphism database (http://www.ncbi.nlm.nih.gov/projects/SNP), Sorting Intolerant from Tolerant (SIFT; http://sift. bii.a-star.edu.sg) and Polyphen-2 (http://genetics.bwh.harvard. edu/pph2). Considering the deduction of an autosomal recessive pattern of inheritance, only the variants that were homozygous or compound heterozygous were selected as candidates.

The variants that met the search criteria were validated by PCR-based Sanger sequencing using the following primers: CDH23 exon 9, forward 5'-TACAACGTGCCCCATTCT GC-3', reverse 5'-GTCTAGGTTCAGCTATGCCGTT-3'; CDH 23 exon 43, forward 5'-TCTTCCGTGGTGGTCCAT TT-3', reverse 5'-AGATGCCTACTGGCTCTCCTT-3'. The TransStart Taq DNA Polymerase kit (Beijing TransGen Biotech Co., Ltd.) was used according to the manufacturers protocol and the thermocycling conditions were as follows: $94^{\circ} \mathrm{C}$ for $2 \mathrm{~min}$, followed by 35 cycles of $94^{\circ} \mathrm{C}$ for $15 \mathrm{sec}$, $55^{\circ} \mathrm{C}$ for $30 \mathrm{sec}, 68^{\circ} \mathrm{C}$ for $2 \mathrm{~min}$. The amplification product was between 200 and $400 \mathrm{bp}$. The data were analyzed using Lasergene-SeqMan software (Lasergene 9; DNAStar, Inc.) and the DNA sequences were compared with the sequence of CDH23 (NM_022124.5) and corresponding $C D H 23$ protein sequences (NP_071407.4). In total, three sequences were compared to establish a consensus.

In silico analysis. Pathogenicity of the missense variants of $\mathrm{CDH} 23$ was predicted by using SIFT and Polyphen-2. The pathogenicity was determined using the following criteria: i) The variants were considered as 'likely damaging or damaging' by either SIFT or Polyphen-2; ii) the variants occurred at the residues that were highly conserved among various species; iii) the variants occurred in affected subjects in homozygous or compound heterozygous phenotypes.

A 3D molecular structure model of the extracellular domain was generated using I-TASSER (http://zhanglab.ccmb. med.umich.edu/I-TASSER) and compared with the confidence score and TM-score using the predicted models. The confidence score is used to estimate the quality of the predicted models using I-TASSER (https://zhanglab.ccmb.med.umich. edu/I-TASSER/) It is calculated based on the significance of threading template alignments and the convergence parameters of the structure assembly simulations. TM-scores are a recently proposed scale for measuring the structural similarity between two structures (24). The DeepView/Swiss-PdbViewer (http://spdbv.vital-it.ch) was used for structural analysis and visualization.

\section{Results}

Patient clinicopathological features. The proband was a 24-year-old female (II:1) that had bilateral hearing loss, and the sibling of the proband was a 17 -year-old male (II:2) with severe deafness. Pure tone audiometry revealed profound sensorineural hearing loss at all frequencies. The patients' parents (I:1 and I:2) had normal hearing, and all other family members exhibited no impairment in movement, vestibular or visual functions.

Genetic analysis. Nine gene loci (GJB2:35delG, 176del16, 235delC, 299delAT, GJB3:538C >T, SLC26A4:2168A>G, IVS7-2A $>\mathrm{G}$, mitochondrial 12SrRNA:1494C $>\mathrm{T}$ and $1555 \mathrm{~A}>\mathrm{G}$ ) were analyzed and none was detected in either of the siblings or in the mother. However, mitochondrial 12SrRNA $1555 \mathrm{~A}>\mathrm{G}$ was detected in the father. Following exclusion of variants of these four genes by Sanger sequencing, the target region capture sequence was used to resolve the genetic causes. Compound heterozygous variants in $\mathrm{CDH} 23$ from the proband were identified following DNA sequencing as one of the two shifts caused by a transition $C D H 23: c .791 A>T$ in exon 9 (Fig. 1). This transition resulted in the substitution of a valine with an aspartic acid at position $264(p . D 264 \mathrm{~V})$. The other variant identified was $C D H 23: c .5853 T>A$ in exon 43. This resulted in the substitution of an aspartic acid for a glutamic acid residue at position 1951 (p.D1951E; Fig. 1). 
The associated regions of $\mathrm{CDH} 23$ were subsequently sequenced in other family members (Fig. 2) and it was revealed that $p . D 264 \mathrm{~V}$ also occurred in the patients' mother. p.D1951E was considered to be a paternal gene, and multiple sequence alignment of the two affected EC domains revealed that the amino acids residues were well-conserved among various species, including Homo sapiens, Mus musculus, Rattus norvegicus and Danio rerio (Fig. 2C).

In silico analysis. Two novel mutations of $\mathrm{CDH} 23$ (c.791A $>T$ and $c .5853 T>A$ ) were identified in the coding region, both of which were missense variants. The data were subsequently scored on the compatibility with the 1000 Genome sequence database, the Single Nucleotide Polymorphism database, SIFT and PolyPhen 2 score (Table I) and according to the scores, the two gene variants were damaged, which was indicated by the comparison with SIFT and Polyphen-2.

3D models of these variants were created and revealed that affected EC domains (containing aspartic acid residues) contained the highly conserved calcium-binding motifs, EC3 and $\mathrm{EC} 18$, in the location of the linking cadherin repeats (Fig. 3). The substitution at residue 264 was the second aspartic acid residue of the DXD calcium-binding motif in EC3. The substitution at residue 1,951 was the first aspartic acid residue of DXNDN calcium-binding motif in EC18. Modeling analysis of the mutated $\mathrm{CDH} 23$ used in the present study revealed that these CDH23 variants were related to DXD and DXNDN motifs. Consistently, DNFB12 mutations were more likely to be involved in the highly conserved regions, such as LDRE, DXNDN and DXD, compared with USH1D (Fig. 4).

\section{Discussion}

Previous studies have indicated that $\mathrm{CDH} 23$ expression is vital for the bundle of hair cells in the cochlea and serves an important role in the establishment and maintenance of the proper organization of the stereocilia $(25,26)$. $C D H 23$ forms a functional network with USH1C, USH1G, CDH23 and myosin VIIA, and participates in mechanotransduction in auditory processing; therefore, $C D H 23$ variants may contribute to hearing loss. The present study identified two novel missense mutations of $C D H 23, c .791 A>T$ and $c .5853 T>A$, in the coding region.

The gene mutation spectrum can be distinguished across different ethnic origins. For example, GJB2:c.35delG occurs more frequently in people of Caucasian origin, whereas GJB2:c.167delT is prevalent in Ashkenazi Jews; GJB2:p. $R 143 W$ was found in an African farmer, and GJB2:c.235delC is commonly reported in East Asian countries $(27,28)$. The frequency of the gene mutations involved in hearing loss is due to the founder effect (1). In the present study, nine gene loci (GJB2:35delG, 176dell6, 235delC, 299delAT, GJB3:538C $>T$, SLC26A4:2168A>G, IVS7-2A>G, mitochondrial 12SrRNA:1494C $>T$ and $1555 A>G$ ) were assessed, but none of these mutations was identified in either affected sibling. However, using the target region captured DNA sequencing technology, two novel pathological $\mathrm{CDH} 23$ variants were identified, which may be possible pathological variants and missense $\mathrm{CDH} 23$ mutations; this was in agreement with previous studies $(11,17,18)$. A previous study demonstrated nonsense, frame shift or splice mutations of $\mathrm{CDH} 23$ in patients

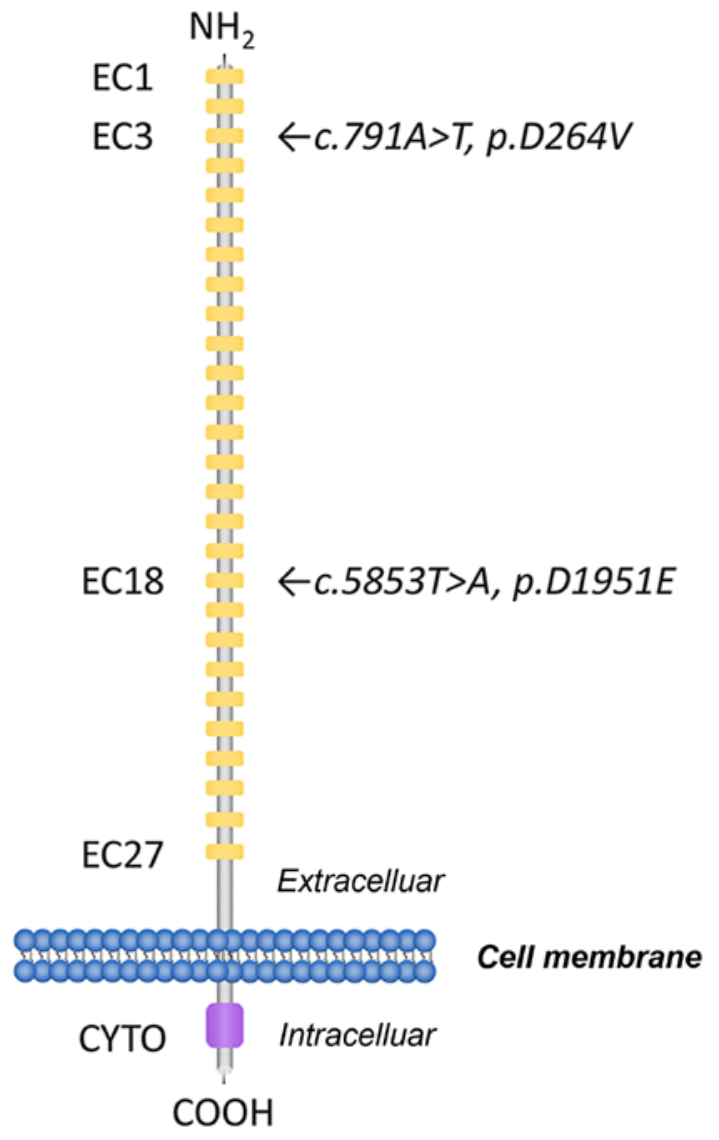

Figure 1. Molecular structure of the human cadherin 23 protein. Positions of the mutated nuclear acids are on the right and the corresponding extracellular repeats are on the left. CYTO, the cytoplasmic domain (purple); EC, extracellular repeat (yellow).

with USH1D (17). Aspartic acid is a medium-sized acidic residue, whereas, valine is hydrophobic. Substitution of the aspartic acid residues with valine strongly reduced the number of oxygen atoms binding to calcium, indicating that these variants may have an effect on $\mathrm{CDH} 23$ structure. Thus, this valine substitution may be pathological in hearing loss. These motifs have been suggested to be essential for a calcium-binding ability, which may influence linearization, rigidification and dimerization of cadherin $(29,30)$.

Calcium ions are usually enclosed by several oxygen atoms (31), and the absence of these atoms normally weakens calcium-binding capacity (32). Substitution of the aspartic acid residues with a valine impaired the interaction of the $\mathrm{CDH} 23$ protein either with itself or with other protein, owing to the loss of oxygen atoms present in aspartic acid. The $c .791 A>T$ mutation involved an amino acid change from an aspartic acid to a hydrophobic valine $(p . D 264 \mathrm{~V})$, which altered the function of the $C D H 23$ protein. In addition, the results of Polyphen-2 and SIFT predicted the impact of these changes and indicated that they may pathogenically affect protein structure or function. Calcium ions serve a crucial role in the process of adaptation of mechanical transduction, frequency tuning, neurotransmitter release and efferent synaptic signaling in the auditory and vestibular systems (33). A previous study has also demonstrated that the $\mathrm{CDH} 23$ protein associates with myosin-1c to form a protein complex that is 
Table I. Pathogenicity prediction of cadherin 23 variants associated with hearing loss using in silico analysis.

\begin{tabular}{lccccccr}
\hline $\begin{array}{l}\text { Nucleotide } \\
\text { change }\end{array}$ & $\begin{array}{c}\text { Amino } \\
\text { acid change }\end{array}$ & Exon & Domain & dbSNP & 1000 Genomes & $\begin{array}{c}\text { Polyphen-2 } \\
\text { score }^{\mathrm{a}}\end{array}$ & $\begin{array}{c}\text { SIFT } \\
\text { score }^{\mathrm{b}}\end{array}$ \\
\hline c.791A $>T$ & p.D264V & 9 & 3 & - & N/A & 0.998 & 0.00 \\
c.5853T>A & $p . D 1951 E$ & 43 & 18 & - & N/A & 0.997 & 0.00 \\
\hline
\end{tabular}

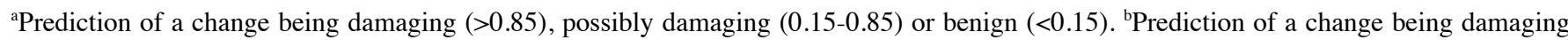
$(<0.05)$ or tolerated. RefSeq NM_022124.5, CDH23 transcript variant 1; NP_071407.4, CDH23 isoform 1 precursor. -, not found; N/A, not applicable; $\mathrm{CDH} 23$, cadherin 23.

A

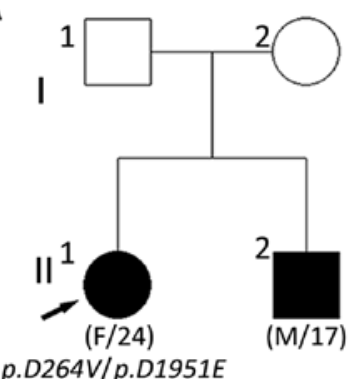

B

II :2

| :

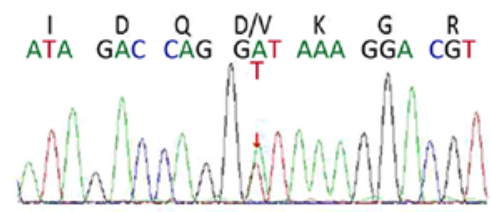

I:1
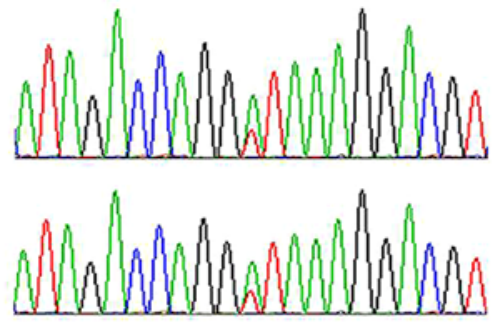

$\begin{array}{llllllll}\text { Homo sapiens } & \text { S } & \text { D } & \text { A } & \text { D } & \text { S } & \text { G } & \text { C } \\ \text { Mus musculus } & \text { V } & \text { D } & \text { Q } & \text { D } & \text { K } & \text { G } & \text { R } \\ \text { Rattus norvegicus V } & \text { D } & \text { Q } & \text { D } & \text { K } & \text { G } & \text { R } \\ \text { Danio rerio } & \text { I } & \text { D } & \text { Q } & \text { D } & \text { L } & \text { G } & \text { R }\end{array}$

Frequency $(\mathrm{Hz})$

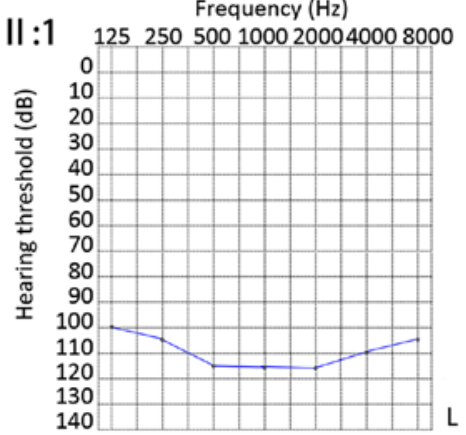

Frequency $(\mathrm{Hz})$

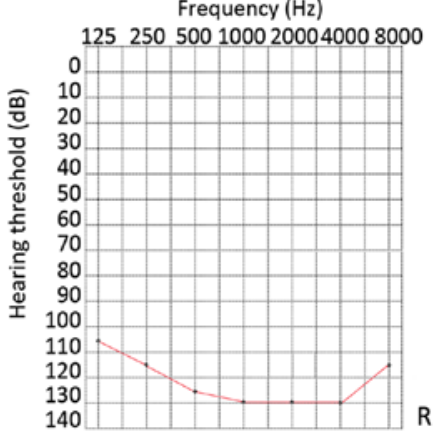

C

p.D1951E

II :1

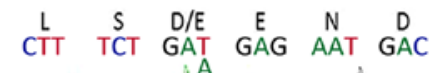

II:2

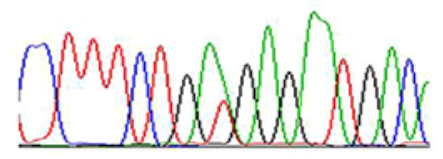

| :2

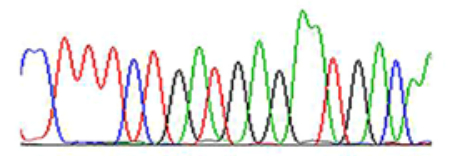

I :1

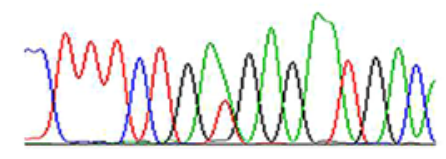

\begin{tabular}{|c|c|c|c|c|}
\hline Homo sapiens & $\mathrm{S}$ & D & $E$ & $\mathrm{~N}$ \\
\hline Mus musculus & A & $\mathrm{D}$ & $E$ & $\mathrm{~N}$ \\
\hline Rattus norvegicus L & A & $D$ & $E$ & $\mathrm{~N}$ \\
\hline Danio rerio & $\mathrm{L}$ & $\mathrm{D}$ & V & $\mathrm{N}$ \\
\hline
\end{tabular}

Figure 2. Identification of $C D H 23$ variants. (A) Patient genealogy. Filled symbols represent hearing-impaired individuals, clear symbols represent individuals with normal hearing ability. The proband, whose left and right ear audiograms are presented, is marked with an arrow. (B) DNA sequencing analysis of $C D H 23$ exon 9 with the heterozygous $c .791 A>T(p . D 264 \mathrm{~V})$ variant and the alignment of the EC3 domain of the $C D H 23$ containing mutation. (C) DNA sequencing analysis of $C D H 23$ exon 43 with a heterozygous $c .5853 T>A$ (p.D1951E) variant and the alignment of the EC18 domain of the $C D H 23$ containing mutation. $C D H 23$, cadherin 23; L, left; R, right.

a component of the mechanotransduction apparatus (34). This suggested that $\mathrm{CDH} 23$ may participate in the activity of mechanically gated ion channels in hair cells. Missense variants of genes, including $\mathrm{CDH} 23$, may be a common cause of disease, depending on the mutation site within the protein. In the present study, two novel $C D H 23$ missense mutations were identified, and the results revealed that there may be an association between gene mutation and disease pathogenicity.
In addition, in silico analysis predicted pathogenic variants of a given gene (35), which was used to demonstrate that the two $C D H 23$ variants may contribute to the hearing impairment of the two patients. Previous studies have revealed that CDH23 variants are associated with hearing loss in Chinese patients. For example, a homozygous c.5985C>A (p.Y1995X) variant has been linked to USH1D (36). Patients from the Chinese Jiangxi province were heterozygous with p.E1006K 
Table II. Frequency of cadherin 23 variants in hearing loss.

\begin{tabular}{|c|c|c|c|c|c|c|c|c|}
\hline \multirow[b]{2}{*}{ Author, year } & \multirow[b]{2}{*}{ Country } & \multirow[b]{2}{*}{$\begin{array}{c}\text { Nucleotide } \\
\text { change }\end{array}$} & \multirow[b]{2}{*}{$\begin{array}{c}\text { Amino } \\
\text { acid change }\end{array}$} & \multicolumn{3}{|c|}{ Number of patients } & \multirow[b]{2}{*}{ No. patients } & \multirow[b]{2}{*}{ (Refs.) } \\
\hline & & & & $-/-$ & $\begin{array}{l}\text { Compc } \\
+/-\end{array}$ & $+/-$ & & \\
\hline Chai et al, 2015 & China & $c .5985 C>A$ & p.Y1995X & 1 & N/A & N/A & 945 & (36) \\
\hline Lu et al, 2014 & China & $\begin{array}{l}c .3016 G>A \\
c .4988 A>T\end{array}$ & $\begin{array}{l}\text { p.E1006K } \\
\text { p.D1663V }\end{array}$ & $\mathrm{N} / \mathrm{A}$ & 2 & N/A & 9 & (37) \\
\hline Miyagawa et al, 2012 & Japan & $\begin{array}{l}c .719 C>T \\
c .902 G>A \\
c .2866 G>A \\
c .4103 C>T \\
c .4249 C>T \\
c .4877 A>C \\
c .5147 A>C \\
c .6085 C>T \\
c .6861 T>G \\
c .7312 G>A\end{array}$ & $\begin{array}{l}p . P 240 L \\
p . R 301 Q \\
p . E 956 K \\
p . T 1368 M \\
p . R 1417 W \\
p . D 1626 A \\
p . Q 1716 P \\
p . R 2029 W \\
p . N 2287 K \\
p . E 2438 K\end{array}$ & $\begin{array}{l}\text { N/A } \\
\text { N/A } \\
\text { N/A } \\
\text { N/A } \\
1 \\
\text { N/A } \\
\text { N/A } \\
2 \\
\text { N/A } \\
\text { N/A }\end{array}$ & $\begin{array}{l}2 \\
3 \\
1 \\
1 \\
\text { N/A } \\
1 \\
3 \\
2 \\
2 \\
1\end{array}$ & $\begin{array}{l}1 \\
\text { N/A } \\
2 \\
\text { N/A } \\
2 \\
\text { N/A } \\
\text { N/A } \\
6 \\
\text { N/A } \\
\text { N/A }\end{array}$ & 1,396 & (19) \\
\hline Woo et al, 2014 & Korea & $\begin{array}{l}c .719 C>T \\
c .1025 A>G \\
c .4783 G>A\end{array}$ & $\begin{array}{l}\text { p.P240L } \\
\text { p.N342S } \\
\text { p.1595K }\end{array}$ & $\begin{array}{l}\text { N/A } \\
\text { N/A } \\
\text { N/A }\end{array}$ & $\begin{array}{l}3 \\
2 \\
1\end{array}$ & $\begin{array}{l}\text { N/A } \\
\text { N/A } \\
\text { N/A }\end{array}$ & 16 & (20) \\
\hline Present study & China & $\begin{array}{l}c .791 A>T \\
c .5853 T>A\end{array}$ & $\begin{array}{l}\text { p.D264V } \\
\text { p.D1951E }\end{array}$ & $\begin{array}{l}\text { N/A } \\
\text { N/A }\end{array}$ & $\begin{array}{l}2 \\
2\end{array}$ & $\begin{array}{l}\text { N/A } \\
\text { N/A }\end{array}$ & 2 & \\
\hline
\end{tabular}

N/A, not applicable.
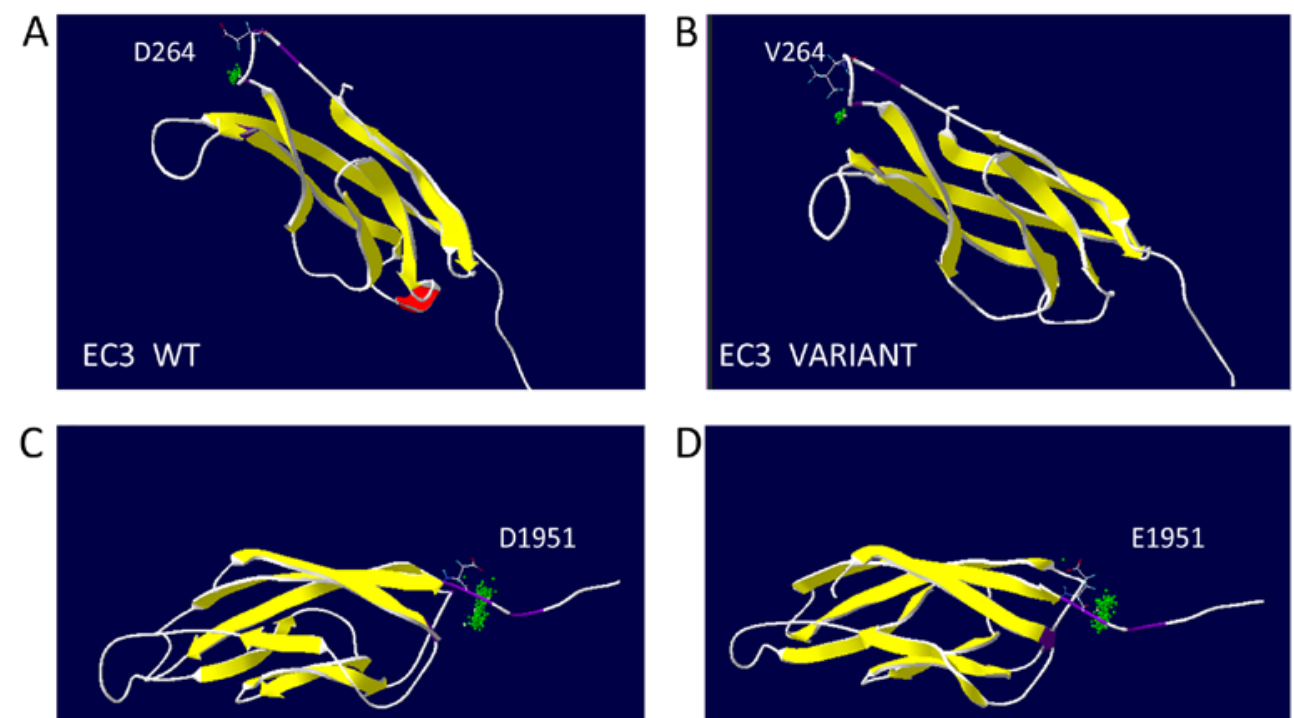

EC18 WT

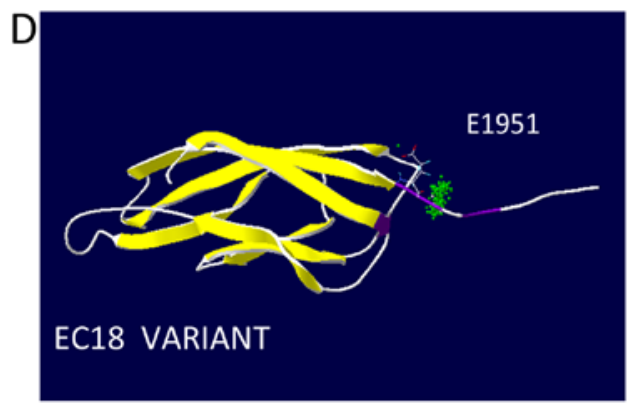

Figure 3. Molecular modeling of $\mathrm{CDH} 23$ extracellular domains 3 and 18. The $\mathrm{CDH} 23$ protein contains various conserved EC domains. The structure of the predicted 3D models reveals a typical folding pattern with several strands (yellow), coils (white) and helices (red). (A and B) Amino acids residues D264 and V264 are localized at EC3. (C and D) Amino acid residues D1951 and E1951 are localized at EC18. The structures of A and C are wild-type, whereas B and D are mutant. The two residues are associated with highly conserved EC calcium-binding sites (purple), whereas the green region represents the possible ligand calcium ion. EC, extracellular.

and p.D1663V in $C D H 23$ (37). Regarding the $C D H 23$ spectrum in the Japanese, the frequency was $3.7 \%$ (including the heterozygous phenotype) in the hearing loss population and
$5.7 \%$ (including the heterozygous phenotype) among the recessive inherited cases (19). Two out of 13 (15\%) Korean families with non-syndromic hearing loss were affected 
DXD

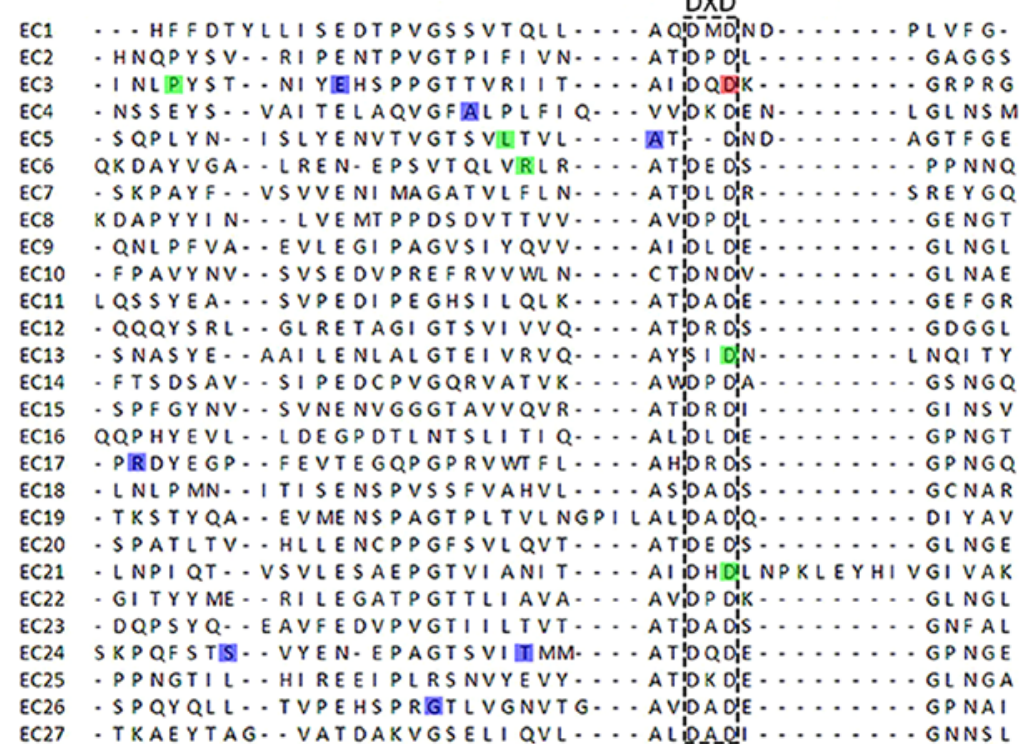

EC1 VS....GEEASRFFAVEPDT....... GVVW. LRQPIDRE EC3 I GYTIVSGNTNSI FALDYIS....... GVLT. LNGL D DRENPLYSHGFIL EC4 FEVYLVG-NNSHHFIISPTSVQG- KADIRIRVAIPID-YEITVDR - YDF ECS VSYFF-SDDPDR-FSLDKDT-......GLIM- LI ARID-YELIIQR - FTL EC6 ITYSIVSASAFGSYFDISLYE-.. GYGVIS-VSRPYD-YEIQISNGLIYL EC7 ESIIYS. LEGSTQFRINARS...... GEIT. TTSLLD. REITKSE. Y Y L EC8 LVYSIQP.. PNKFYSLNSTTG... KI RTTH. AML DRENPA'PHEAELMRK EC9 VSYRMPVGMPRMD. . FLINS - . . SSGVVV.TTTELD.RERIAE. . YQL EC10 LSYFITGGNVDGKFSVGYRDA...VVVRTV...VG. ID. REITTAA. YML EC11 VWYRIL HGNHGNNFRI HVSNG...LLL. MR - GPRPID.RETRNSS . HVL EC12 VNYRILSG.AEGKFEIDEST....... GLII. TVNYID. YEITKTS . YMM EC13 RFNAYTSTQAKALFKIDAIT....... GVIT - VQGLND-REIKGDF - YTL EC14 VVFSLASGNIAGAFEIVTTND...SIGEVF-VARPID-REIELDH. - YI I EC1S LSYYITEGNKDMAFRMDRISG... EI ATR . . PAPPD.RERRSF . Y YL EC16 VTYAIVAGNIVNTFRIDRHM. . . . . GVIT. AAKEID. YEIISHGR.YT EC17 VEYSI MDGDPLGEFVI SPVEG... VLRVRK. DVEID. REITI AF . Y Y EC18 LTFNI TAGNRERAFFINATT..... GIVT.VNRPID.REIRI PE. . YKL EC19 VTYQLLG.AQSGLFDINSSTG....VVVTVR-SGVI D.REAFSPPILEL EC2O LVYRIEAG. AQDRFLI HLVTG...VVIRVG... NATID.REEQES. Y YRL EC21 DDTDRLVPNQEDAFAVNINT - . . . GSVM-VKSPTMN-REGLVAT - YEV EC22 VTYTLLDLVPPGY - VQLEDS - . . SAGKVI. ANRTVD-YEIEVHW - L NF EC23 IEYS. - LGDGESKFAINPTT....... GDIY.VLSSID.REIKKDH. - YII EC24 LTYSLEGPGVEAFHVDMDS......... GLVT. TQRP Q QSYEIKFS. . . . L EC2S VRYSFLKTAGNRDWEFFII DP.... ISGLI Q. TAQRL D. REISQAV. . YSL

EC26 VYYFI AAGINEEKNFHLQPDGC...LLL VLL..RDLD.REIREAI . FSF

EC27 VFYSILAI HYFRALANDSEDVGQVFTMGSMDGILRT'LDLFNAYSPGYFVV

\begin{tabular}{|c|c|}
\hline EC1 & TVEFSVSDHQG............. TI TRKVNI QVGDVNDNAPTF \\
\hline $\mathrm{C2}$ & QLTVNAT-DQ-DKTRPLST........ LANLAIIITDVQDMDPIF \\
\hline EC3 & LTVKGTELNDDRTPSDAT ........VTTTFNI LVIDI NDNAPEF \\
\hline EC4 & DFDLFANESVP... DHVG . . . . . YAKVKI TLI 'NENDNRPIF \\
\hline ECS & 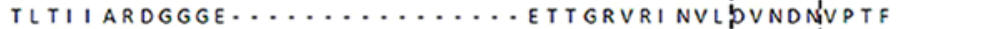 \\
\hline c6 & 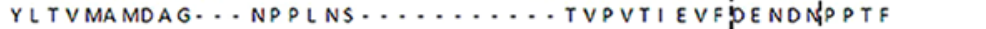 \\
\hline EC7 & 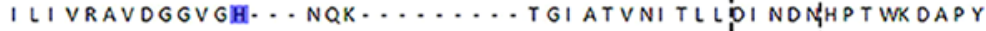 \\
\hline EC8 & RKIVVSVTDCGRPPLKATS $\cdots \cdots . .$. SATVFVNLL \\
\hline C9 & 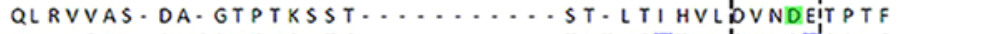 \\
\hline c10 & MLI LEAI - DNGPVGKRHTG........ TATVFVTVL \\
\hline c11 & VLIVEAY - NH-DLGPMRSS . . . . . V VRVIVYVE \\
\hline EC12 & MMNVSATDQAPPFNQGFCS $\cdots \cdots \cdots$ VYITLL $\cdots N$ \\
\hline EC13 & ........ DSTVKVY \\
\hline EC14 & D........... HI L QVTIL \\
\hline EC15 & 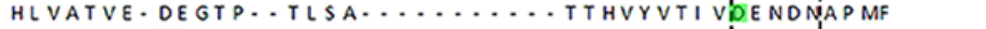 \\
\hline EC16 & TLIVTATDQCPILSHRLTS ......... TTTVLVNVNDI NDNVPTF \\
\hline EC17 & 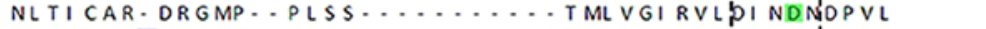 \\
\hline C18 & 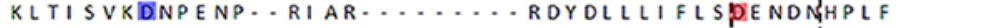 \\
\hline EC19 & 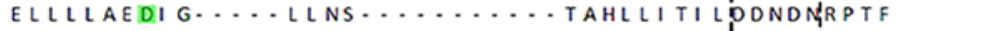 \\
\hline $\mathrm{c} 20$ & 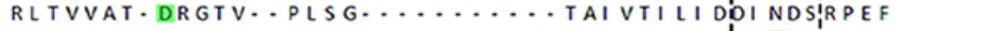 \\
\hline 021 & EVTLSVI DNASDLPERSVS $\cdots \cdots$. . . VPNAKLTVNVL \\
\hline EC22 & NFTVRAS - D. NGSPPRAA …... EI PVYLEI \\
\hline $\mathrm{C23}$ & I LTALAKDNPGDVA-SNRR...... ENSVQVVI QV \\
\hline 24 & LWG ......... TT TML L VEV \\
\hline 25 & $S L I L V A S \cdot D L \cdot G Q P V A$ \\
\hline $\mathrm{C} 26$ & SFIVKASSNR-SWTPPRGPS \\
\hline & YILLRDDQRVKIVI \\
\hline
\end{tabular}

Figure 4. Alignment of CDH23 EC domains with mutations causing Usher syndrome type ID and recessive DBNF12. DNASTAR Lasergene analysis was used to align $27 \mathrm{EC}$ domains. The corresponding EC domains are indicated on the left. The LDRE, DXNDN and DXD calcium-binding motifs are boxed. The sites of mutations identified in the present study are highlighted in red, whereas the sites of mutations identified by other studies are highlighted in green (DBNF12) and blue (Usher Syndrome type 1). 
by $C D H 23$ mutations in an autosomal recessive pattern and three of 93 patients exhibited a heterozygous phenotype (20). Consequently, some $\mathrm{CDH} 23$ variants frequently occurred in certain ethnic origins $(19,20)$ and, based on these data, it was speculated that $\mathrm{CDH} 23$ variants may be an important cause of hearing loss in Asian populations (Table II). Although the precise pathogenesis and molecular mechanism of hearing have not been defined, the data from the present study and the literature indicate that DFNB12 $\mathrm{CDH} 23$ variants may impact the Chinese population with non-syndromic hearing loss.

In conclusion, the present study identified two novel CDH23 mutations in one Chinese family with autosomal recessive non-syndromic hearing loss using the target region captured DNA sequencing. However, the exact frequency requires further investigation as only data from two generations of this family were obtained. Future studies with a larger cohort of patient samples are needed to confirm the present results, which may be used for early detection of hearing loss. In addition, target region captured DNA sequencing technology may be effective for detecting causative gene variants in patients with no mutations in GJB2, GJB3, SLC26A4 and mitochondrial 12SrRNA.

\section{Acknowledgements}

Not applicable.

\section{Funding}

No funding was received.

\section{Availability of data and materials}

The datasets used and/or analyzed during the present study are available from the corresponding author on reasonable request.

\section{Authors' contributions}

All authors made substantial contributions to conception and design, or acquisition of data, or analysis and interpretation of data. TX, HL and SY performed the experiments. TX drafted the article. PW and WZ critically revised the article. $Z W$ reviewed the submitted version of manuscript. All authors read and approved the final manuscript.

\section{Ethics approval and consent to participate}

The study was approved by the Ethics Committee of the First Hospital of Jilin University (Changchun, China) and all participants provided written informed consent prior to being enrolled in the study.

\section{Patient consent for publication}

Written informed consent was obtained from the parent of the patient for the publication of this case report.

\section{Competing interests}

The authors declare that they have no competing interests.

\section{References}

1. Shearer AE, Hildebrand MS and Smith RJH: Hereditary hearing loss and deafness overview. In: Adam MP, Ardinger $\mathrm{HH}$, Pagon RA, Wallace SE, Bean LJH, Stephens K, Amemiya A, editors. GeneReviews ${ }^{\circledR}$ [Internet]. Seattle (WA): University of Washington, Seattle; 1993-2019.

2. GBD and 2015 Disease and Injury Incidence and Prevalence Collaborators: Global, regional, and national incidence, prevalence, and years lived with disability for 310 diseases and injuries, 1990-2015: A systematic analysis for the global burden of disease study 2015. Lancet 388: 1545-1602, 2016.

3. Cunningham LL and Tucci DL: Hearing loss in adults. N Engl J Med 377: 2465-2473, 2017.

4. Olusanya BO, Neumann KJ and Saunders JE: The global burden of disabling hearing impairment: A call to action. Bull World Health Organ 92: 367-373, 2014.

5. Smith RJH, Bale JF Jr and White KR: Sensorineural hearing loss in children. Lancet 365: 879-890, 2005.

6. Paludetti G, Conti G, Di Nardo W, De Corso E, Rolesi R, Picciotti PM and Fetoni AR: Infant hearing loss: From diagnosis to therapy official report of XXI conference of italian society of pediatric otorhinolaryngology. Acta Otorhinolaryngol Ital 32: 347-370, 2012.

7. Friedman TB and Griffith AJ: Human nonsyndromic sensorineural deafness. Annu Rev Genomics Hum Genet 4: 341-402, 2003.

8. Hilgert N, Smith RJ and Van Camp G: Function and expression pattern of nonsyndromic deafness genes. Curr Mol Med 9: 546-564, 2009.

9. Morton NE: Genetic epidemiology of hearing impairment. Ann N Y Acad Sci 630: 16-31, 1991.

10. Funamura JL: Evaluation and management of nonsyndromic congenital hearing loss. Curr Opin Otolaryngol Head Neck Surg 25: 385-389, 2017.

11. Bork JM, Peters LM, Riazuddin S, Bernstein SL, Ahmed ZM, Ness SL, Polomeno R, Ramesh A, Schloss M, Srisailpathy CR, et al: Usher syndrome 1D and nonsyndromic autosomal recessive deafness DFNB12 are caused by allelic mutations of the novel cadherin-like gene CDH23. Am J Hum Genet 68: 26-37, 2001.

12. Bolz H, von Brederlow B, Ramirez A, Bryda EC, Kutsche K, Nothwang HG, Seeliger M, del C-Salcedó Cabrera M, Vila MC, Molina OP, et al: Mutation of CDH23, encoding a new member of the cadherin gene family, causes Usher syndrome type 1D. Nat Genet 27: 108-112, 2001.

13. Rowlands TM, Symonds JM, Farookhi R and Blaschuk OW: Cadherins: Crucial regulators of structure and function in reproductive tissues. Rev Reprod 5: 53-61, 2000.

14. Di Palma F, Holme RH, Bryda EC, Belyantseva IA, Pellegrino R, Kachar B, Steel KP and Noben-Trauth K: Mutations in Cdh23, encoding a new type of cadherin, cause stereocilia disorganization in waltzer, the mouse model for Usher syndrome type 1D. Nat Genet 27: 103-107, 2001.

15. Boëda B, El Amraoui A, Bahloul A, Goodyear R, Daviet L, Blanchard S, Perfettini I, Fath KR, Shorte S, Reiners J, et al: Myosin VIIa, harmonin and cadherin 23, three usher I gene products that cooperate to shape the sensory hair cell bundle. EMBO J 21: 6689-6699, 2002.

16. Siemens J, Kazmierczak P, Reynolds A, Sticker M, LittlewoodEvans A and Müller U: The usher syndrome proteins cadherin 23 and harmonin form a complex by means of PDZ-domain interactions. Proc Natl Acad Sci USA 99: 14946-14951, 2002.

17. Astuto LM, Bork JM, Weston MD, Askew JW, Fields RR, Orten DJ, Ohliger SJ, Riazuddin S, Morell RJ, Khan S, et al: CDH23 mutation and phenotype heterogeneity: A profile of 107 diverse families with usher syndrome and nonsyndromic deafness. Am J Hum Genet 71: 262-275, 2002.

18. Wagatsuma M, Kitoh R, Suzuki H, Fukuoka H, Takumi Y and Usami S: Distribution and frequencies of $\mathrm{CDH} 23$ mutations in Japanese patients with non-syndromic hearing loss. Clin Genet 72: 339-344, 2007.

19. Miyagawa M, Nishio SY and Usami S: Prevalence and clinical features of hearing loss patients with $\mathrm{CDH} 23$ mutations: A large cohort study. PLoS One 7: e40366, 2012.

20. Woo HM, Park HJ, Park MH, Kim BY, Shin JW, Yoo WG and Koo SK: Identification of CDH23 mutations in Korean families with hearing loss by whole-exome sequencing. BMC Med Genet 15: 46, 2014. 
21. Alford RL, Arnos KS, Fox M, Lin JW, Palmer CG, Pandya A, Rehm HL, Robin NH, Scott DA, Yoshinaga-Itano C, et al: American college of medical genetics and genomics guideline for the clinical evaluation and etiologic diagnosis of hearing loss. Genet Med 16: 347-355, 2014.

22. McKenna A, Hanna M, Banks E, Sivachenko A, Cibulskis K, Kernytsky A, Garimella K, Altshuler D, Gabriel S, et al: The Genome Analysis Toolkit: a MapReduce framework for analyzing next-generation DNA sequencing data. Genome research 20: 1297-1303, 2010.

23. Huang XF, Xiang P, Chen J, Xing DJ, Huang N, Min Q, Gu F, Tong Y, Pang CP, Qu J and Jin ZB: Targeted exome sequencing identified novel USH2A mutations in Usher syndrome families. PloS One 8: e63832, 2013.

24. Zhang Y and Skolnick J: Scoring function for automated assessment of protein structure template quality. Proteins 57: 702-710, 2004.

25. Siemens J, Lillo C, Dumont RA, Reynolds A, Williams DS, Gillespie PG and Müller U: Cadherin 23 is a component of the tip link in hair-cell stereocilia. Nature 428: 950-955, 2004.

26. Müller U: Cadherins and mechanotransduction by hair cells. Curr Opin Cell Biol 20: 557-566, 2008.

27. Tsukada K, Nishio S and Usami S; Deafness Gene Study Consortium. A large cohort study of GJB2 mutations in Japanese hearing loss patients. Clin Genet 78: 464-470, 2010.

28. Van Laer L, Coucke P, Mueller RF, Caethoven G, Flothmann K, Prasad SD, Chamberlin GP, Houseman M, Taylor GR, Van de Heyning CM, et al: A common founder for the 35delG GJB2 gene mutation in connexin 26 hearing impairment. J Med Genet 38: 515-518, 2001.

29. Nagar B, Overduin M, Ikura M and Rini JM: Structural basis of calcium-induced E-cadherin rigidification and dimerization. Nature 380: 360-364, 1996.
30. Angst BD, Marcozzi C and Magee AI: The cadherin superfamily: Diversity in form and function. J Cell Sci 114: 629-641, 2001

31. Strynadka NC and James MN: Crystal structures of the helix-loophelix calcium-binding proteins. Annu Rev Biochem 58: 951-998, 1989.

32. Chakrabarti P: Systematics in the interaction of metal ions with the main-chain carbonyl group in protein structures. Biochemistry 29: 651-658, 1990.

33. Yamoah EN, Lumpkin EA, Dumont RA, Smith PJ, Hudspeth AJ and Gillespie PG: Plasma membrane Ca2+-ATPase extrudes Ca2+ from hair cell stereocilia. J Neurosci 18: 610-624, 1998.

34. Holt JR, Gillespie SK, Provance DW, Shah K, Shokat KM, Corey DP, Mercer JA and Gillespie PG: A chemical-genetic strategy implicates myosin-1c in adaptation by hair cells. Cell 108: 371-381, 2002.

35. Richards S, Aziz N, Bale S, Bick D, Das S, Gastier-Foster J, Grody WW, Hegde M, Lyon E, Spector E, et al: Standards and guidelines for the interpretation of sequence variants: A joint consensus recommendation of the american college of medical genetics and genomics and the association for molecular pathology. Genet Med 17: 405-424, 2015.

36. Chai Y, Chen D, Sun L, Li L, Chen Y, Pang X, Zhang L, Wu H and Yang T: The homozygous p.V37I variant of GJB2 is associated with diverse hearing phenotypes. Clin Genet 87: 350-355, 2015.

37. Lu Y, Zhou X, Jin Z, Cheng J, Shen W, Ji F, Liu L, Zhang X, Zhang M, Cao Y, et al: Resolving the genetic heterogeneity of prelingual hearing loss within one family: Performance comparison and application of two targeted next generation sequencing approaches. J Hum Genet 59: 599-607, 2014.

(i) $\Theta$ This work is licensed under a Creative Commons c) Attribution-NonCommercial-NoDerivatives 4.0 International (CC BY-NC-ND 4.0) License. 